\title{
Quantitative Determination of Urinary Gonadotropin Inhibiting Material (GIM) in Health and Lesions of Hypothalamic-Hypophyseal Axis
}

\author{
SHAH PRABHAKER N. AND Kothari LALITA S. \\ Department of Endocrinology Cancer Research Institute \\ Parel, Bombay-12 INDIA
}

\begin{abstract}
Synopsis
In this paper quantitative determination of GIM in 30 apparently healthy subjects and 15 subjects with functional or organic alternations in the hypothalamic-hypophyseal axis is detailed. From the observations on the quantitation of GIM in the varied clinical states the authors conclude that the hypothalamic region contributing GIM is different from that controlling the secretion and release of gonadotropins. This preliminary data also suggest that the quantitative determination of GIM may help to delineate hypogonadotropic hypogonadism due to pituitary disease from the hypothalamic etiology.
\end{abstract}

As stated elsewhere, the preliminary work from this Laboratory suggests that the site of origin of GIM, in all probability, appears to be the hypothalamus although its physiological significance is far from clear (Mahajan and Shah 1970). However, in absence of microtechnique for direct measurement in systemic blood and of our knowledge of its chemical composition, one has to be satisfied with studies of its excretory pattern in the urine as measured by bioassay procedures (Landau et al., 1960; Ota et al., 1967). This short communication presents our findings on the quantitative determination of urinary GIM in functional or organic alterations of the hypothalamus. In this series some cases of secondary hypogonadism (with or without pathological changes in sella turcica) are also included with the purpose to correlate excretory levels with the involvement of hypothalamus, if any.

\section{Material and Methods}

GIM was extracted from 24-hr urine specimens from 30 apparently healthy subjects. Thymol was

Received for publication July 20, 1970. used as a preservative while collection and the collected urine was stored at $4{ }^{\circ} \mathrm{C}$ before extraction. The details of the method of extraction and quantitative measurement of GIM are published elsewhere (Mahajan and Shah 1970).

For the gonadotropin assay, the whole 24-hr urine sample collected on ice was extracted by the method of Butt (1958). The extract was bioassayed, using random bred, Kasuali albino immature female mice of 21-22 days weighing 8-10 gms. In our Laboratory one Mouse Uterine Unit was considered to be equivalent to the amount that would give 100-200\% increase in uterine weight as compared to that seen in control animals injected with only distilled water.

\section{Observations and Discussion}

The results on the apparently healthy subjects are summarised in Table 1 . It can be seen that debarring two menopausal women, urine of almost all the apparently healthy subjects revealed significant inhibition $(60 \%$ or more) of the growth promoting activity of the human chorionic gonadotropin as judged from the mouse uterine weight. Therefore, while considering alterations in the excretory levels in GIM, absence of significant inhibition in one, two or four hourly urinary extracts denote decrease in GIM. In each 
Table 1. Gonadotropin inhibiting activity in urine in normal subjects (30)

\begin{tabular}{|c|c|c|c|c|c|}
\hline \multirow{3}{*}{ Sample } & \multirow{3}{*}{ (No. of cases) } & \multirow{3}{*}{ Age (Range) } & \multicolumn{3}{|c|}{$\begin{array}{l}\text { Ratio of cases in which satisfactory reduction } \\
(60 \% \text { or more }) \text { in stimulated uterine weight }\end{array}$} \\
\hline & & & \multicolumn{3}{|c|}{ Doses } \\
\hline & & & $4 \mathrm{Hr}^{*}$ & $2 \mathrm{Hr}$ & $1 \mathrm{Hr}$ \\
\hline Children & (12) & $6-11$ & $12 / 12$ & $12 / 12$ & $12 / 12$ \\
\hline Women ... & (14) & & & & \\
\hline Menstruating & (9) & $18-31$ & $9 / 9$ & $9 / 9$ & $9 / 9$ \\
\hline Menopausal & (5) & $52-61$ & $5 / 5$ & $4 / 5$ & $3 / 5$ \\
\hline Men ..... & (4) & $23-29$ & $4 / 4$ & $4 / 4$ & $4 / 4$ \\
\hline Total Subjects & (30) & & $30 / 30$ & $29 / 30$ & $28 / 30$ \\
\hline
\end{tabular}

* Hr: Hourly urine extract

instance where such decrease was found in a 4 hourly urinary extract, further testing on a 8 hourly extract of urine was made using the same biological end point. On the other hand, elevated levels of GIM, theoretically speaking, can be evidenced by the significant inhibition of the uterine weight in 30 and 15 min equivalent extracts of urine.

The unequivocal presence of GIM in 4,2 and one hourly extracts of urine in both the sexes and at all ages raises the question whether such data on varying amounts of GIM extracted in certain physiological and pathophysiological states can be exploited to understand its metabolic pathway, as well as in elucidation of its physiological role. With the exceptions of the present study, the authors are not aware of any study made to quantitate urinary GIM. There are however a few stray reports where GIM was found to be absent (Soffer et al., 1965; Soffer and Fogel 1964).

The findings on GIM excretion in subjects with functional or organic alterations of the hypothalamic-hypophyseal axis are summarised in Table 2. It is evident that the excretory level of GIM in two patients (CS $\& \mathrm{KD}$ ) harbouring suprasellar tumour with extent on towards hypothalamus was markedly decreased in one and was present in low amounts in the other. The total urinary gonadotropins however were normal in the patient (CS) who was having cyclic bleeding.
On the other hand KD (aged 11 years) having pineal tumour did not show any signs of precocious puberty or detectable levels of urinary gonadotropins.

Similarlyin the group of 3 apparently healthy children with presumably normal hypothalamic-hypophyseal axis, under parenteral medroxyprogesterone acetate, there was total absence of GIM in one case (DA), partial but insignificant inhibition in the other (KA) while only the 4 hourly extract of urine of the remaining one case (RS) exhibited significant inhibition. In both DA and KA, the 8 hourly urine extracts also did not reveal significant inhibition. One of them (RS) who had already menarche and evidence of having normal amount of gonadotropins in the urine prior to treatment showed definite suppression in the level of gonadotropins in the posttreatment urine specimens. This posttreatment suppression in gonadotropins appears to be of central in origin and is most probably through hypothalamic neurohumour mechanism. (Reichlin 1968). Another central nervous system action of medroxyprogesterone acetate observed in man is the stimulation of prolactin release by inhibiting the prolactin inhibitory mechanism at the hypothalamus (Pasteels and Ectors 1967). From the foregoing it appears that there was a definite reduction in GIM excretion in these children under treatment with medroxyprogesterone acetate which is an extremely 
Table 2. GIM and gonadotropins in patients with lesions of hypothalamic-hypophyseal axis (15)

\begin{tabular}{|c|c|c|c|c|c|c|c|c|}
\hline \multirow{3}{*}{ Subject } & \multirow[b]{3}{*}{ Sex } & \multirow{3}{*}{ Age } & \multicolumn{4}{|c|}{ GIM } & \multicolumn{2}{|l|}{ Urinary gonadotropins } \\
\hline & & & \multicolumn{4}{|c|}{ Percent reduction at } & \multirow{2}{*}{$\begin{array}{l}\text { m.u.u. } / 24 \mathrm{hr} \\
\text { (Normal range } \\
6-30 \text { m.u.u.) }\end{array}$} & \multirow[t]{2}{*}{ Diagnosis } \\
\hline & & & $8 \mathrm{Hr}$ & $4 \mathrm{Hr}$ & $2 \mathrm{Hr}$ & $1 \mathrm{Hr}$ & & \\
\hline C.S. & $\mathrm{F}$ & 25 & Nil* & Nil & Nil & Nil & $>20.0 \&<30.0$ & Suprasellar Tumour \\
\hline K.D. & M & 11 & 70.0 & 57.4 & 27.0 & Nil & $<4.0^{* *}$ & Pineal Tumour \\
\hline D.A. & $\mathbf{M}$ & 8 & Nil & Nil & Nil & Nil & $<4.0$ & Rx Depo-provera \\
\hline K.A. & $\mathrm{F}$ & 11 & 29.1 & 27.6 & 24.5 & 23.9 & $<4.0$ & -"- \\
\hline R.S. & $\mathrm{F}$ & 13 & - & 65.0 & 38.5 & 32.4 & $<4.0$ & -"'- \\
\hline D.B. & $\mathrm{F}$ & 21 & - & 77.5 & 70.5 & 70.0 & $<4.0$ & Intrasellar Tumour \\
\hline S.L. & $\mathrm{F}$ & 25 & 一 & 80.9 & 81.6 & 83.7 & $<4.0$ & $-"$ \\
\hline S.M. & $\mathbf{M}$ & 48 & 一 & 62.9 & 57.6 & 3.6 & $>4.0 \&<5.0$ & $-"$ \\
\hline K.S. & $\mathrm{F}$ & 38 & 77.4 & 51.6 & - & - & $<4.0$ & $-"$ \\
\hline R.R. & $\mathrm{F}$ & 26 & 47.0 & 46.0 & 22.0 & 14.3 & $>4.0 \&<5.0$ & -’- \\
\hline J.K. & $\mathrm{M}$ & 27 & - & 71.5 & 43.5 & 28.4 & $>4.0 \&<5.0$ & Secondary Hypogonadism \\
\hline B.A. & $\mathbf{M}$ & 24 & - & 80.6 & 63.2 & 63.4 & $<4.0$ & -"- \\
\hline M.M. & $\mathbf{M}$ & 22 & - & 72.0 & 60.1 & 32.1 & $>4.0 \&<5.0$ & $\therefore$ \\
\hline N.D. & $\mathbf{M}$ & 26 & 29.1 & 18.2 & 12.2 & 13.3 & $<4.0$ & $\therefore$ \\
\hline S.S. & $\mathrm{M}$ & 26 & 41.0 & 26.3 & 21.9 & 10.5 & $<4.0$ & $\therefore$ \\
\hline
\end{tabular}

* $10 \%$ reduction

** The lowest level detectable in our laboratory

- Not estimated

potent long acting progestational agent. However, the excretory pattern of GIM varied from subject to subject and it is difficult to speculate whether this effect is due to variable individual sensitivity of the hypothalamus or to variation in the degree of response to medroxyprogesterone acetate.

In the group of 5 patients having intrasellar tumour it can be seen that two of the five (DB, SL) had only normal excretory levels of GIM while in one further patient SM, one hourly extract inparticularly, lacked the presence of adequate amount of GIM as seen from their ability to inhibit the stimulated uteri. In the remaining two patients, (KS and RR) GIM in the 4 hourly extracts was definitely decreased, and the 8 hourly extract of one of these (RR) also did not have sufficient quantity of GIM to have satisfactory inhibition. As seen macroscopically, in two of these 3 patients there was a definite suprasellar extension of the tumour towards hypothalamus which probably explains the observed decrease in the amount of GIM.

The absence or/ presence of very low amounts of GIM in a normally menstruating woman, harbouring a suprasellar tumour and in a boy with pineal tumour not showing precocious puberty is intriguing. In both these cases, the tumour was known to extend into hypothalamus. Similarly 2 of the 3 patients having intrasellar tumour and diminution in GIM excretion, on detailed investigations, had extension of the tumour towards the hypothalamus. From all these findings on patients wherein there is evidence of hypothalamic involvement with or without the normal excretory pattern of urinary gonadotropins and/or menstrual function, one can speculate safely that the hypothalamic region contributing GIM is different from that regulating the secretion and release of gonadotropins.

In other group of 5 patients having secondary hypogonadism, and normal looking sella turcica, 2 out of 5 patients (ND and SS) did not have adequate amount of GIM to demonstrate significant inhibition of stimulated uteri even their 8 hourly extracts in two additional patients, (JK and MM) significant 
inhibition was absent at the other two levels of testing viz two and/or one hourly extracts. The aforementioned findings in the absence or presence of the low levels of urinary gonadotropins indicate that the level of GIM in all these cases having normal looking sella turcica was decreased.

Of these cases, ND in particularly categorised under Kallman's syndrome or "olfactory-genital-dysplasia" wherein primary neurogenic disorder is associated with hypogonadotropic hypogonadism. Pathological examination of the brains of such individuals reveals that the anosmia is due to agenesis of the olfactory lobes. (Kallmann et al., 1944) Failure to develop gonadotropic function is very probably due to maldevelopment of the gonadotropin regulating areas of the hypothalamus which are anatomically and physiologically very closely connected with the rhinencephalon. Thus, delineation between hyponadotropic hypogonadism due to pituitary desease and that associated with maldevelopment of functional disorder or the hypothalamus may be possible with the help of the quantitative determination of GIM. In otherwords the decrease in GIM in these cases may be explained on the basis of the functional alterations in the hypothalamus. There is no doubt that the largest proportion of men with hypogonadotropic hypogonadism do not have clinically detectable structural disease of the pituitary gland and have otherwise normal pituitary function. Again experimental work in animals do suggest that such cases can occur due to failure of proper maturation of hypothalamic-gonadotropin regulation areas (Reichlin 1968). This speculative view, indeed can be confirmed on the basis of the decrease in GIM in some cases of hypogonadotropic hypogonadism. However, since the area contributing GIM is different from that regulating the secretion and release of gonadotropins, one may meet situations where quantitation in GIM may not be any different from those seen in normal individuals. It is therefore felt that further research in this area of neuroendocrine diseases will greatly facilitate recognition of cases arising from neurogenic causes from those arising out of disturbances of the anterior pituitary gland.

\section{References}

Butt, W. R. (1958). J. Endocrinol. 7, 143. Kallmann, F. J., W. A. Schoenfeld and S. E. Barrera (1944). A. m.J. Ment. Defic. 49, 203.

Kupperman, H. S. and J. A. Epstein (1962). J. Clin Endocrinol. 22, 456.

Landau, B., H. S. Schwartz and L. J. Soffer (1960). Metabolism 9, 85.

Mahajan, D. K. and P. N. Shah (1970). Ind. J. Med. Res. 58, 308.

Ota, M., A. Dronkert and K. Obara: Proc. of the Third Asia \& Oceania Congress of Endocrinology Manila pp. 681 (1967). Pasteels, J. L. and F. Ectors (1967). C. R. Acad. Sci. (Paris) 264, 106.

Reichlin, S. In Text book of Endocrinology (Edited by R. H. Williams) W. B. Saunders Company, Philadelphia pp. 967 (1968). Soffer, L. J. and M. Fogel (1964). J. Clin. Endocrinol. 24, 656.

Soffer, L. J., M. Fogel and A. Z. Rudavsky (1965). Acta Endocrinol. 48, 561. 